\title{
HIGH SPEED SYNCHRONOUS RELUCTANCE DRIVES FOR MOTOR SPINDLES
}

\author{
M. Weber ${ }^{1 *}$, M. Weigold ${ }^{1}$ \\ ${ }^{1}$ Technische Universität Darmstadt, Institute of Production Management, Technology and Machine Tools (PTW), \\ Darmstadt, Germany \\ *Corresponding author; e-mail: m.weber@ptw.tu-darmstadt.de
}

\begin{abstract}
This article presents a new design for setting up high speed synchronous reluctance motors (SynRM) in motor spindle applications for up to $30,000 \mathrm{rpm}$. The transversal laminated SynRM rotor package is supported by thin steel sheets and a shaft nut to exert a constant axial clamping force. Both, numerical and practical investigations are carried out using FEM-analysis and a test bench for centrifugal force load tests. The objective is to find out at which speed the elastic deformation changes into the plastic deformation. The beginning of plastic deformation is a failure criterion in electric motor construction.
\end{abstract}

\section{Keywords:}

High speed machining; Synchronous reluctance drive; Motor spindle

\section{INTRODUCTION}

The focus on high speed machining has reached a new level. New process strategies using industrial robots for hybrid manufacturing processes consisting of wire cladding and high speed finishing come up with specific requirements for the spindle system: low torque, high cutting speed and high stiffness [Abele 2018]. In addition political efforts grow to define energy efficiency standards for power driven equipment in the IEC 61800-9-1:2017 which can be applied to machine tools [IEC 61800-9-1 2017]. Therefore the development of energy efficient high speed motor spindles is a key-aspect in the future. Synchronous reluctance motors (SynRM) are established for pump and fan applications with speeds up to 6,000 rpm. The efficiency classes of these variable speed AC motors are defined in IEC TS 60034-30-2:2016 [IEC TS 60034-302 2016]. For higher spindle speeds the electrical sheet's yield strength is a limiting factor for the mechanical strength of the flux barrier rotor design. In 2017, Sielaff set up a SynRM-spindle for $14,000 \mathrm{rpm}$ using axial rods made of carbon fiber-reinforced plastic to avoid radial deformation of the rotor [Sielaff 2017]. In this article new numerical and practical results will be presented on how to design SynRMrotors for high speed motor spindles of up to $30,000 \mathrm{rpm}$ in order to benefit from the field weakening potential of the SynRM due to flux reduction (see Fig. 1).

\begin{tabular}{|c|c|}
\hline $\mathbf{D}$ [Sielaff 2017] & O[KSB 2019] \\
\hline$\Delta[$ Siemens 2019] & $\bullet$ [ABB 2019] \\
\hline [Moghaddam 2011] & [Matsuo 1993] \\
\hline $\boldsymbol{\Delta}$ [Boglietti 2005] & [Sebest 2016] \\
\hline * [Neusüs 2018] & $\square[$ Boldea 1991] \\
\hline$\diamond[$ Winkler 2018] & [ [Weber 2019] \\
\hline ○[Reddy 2015] & $\diamond[$ Hofer 2017] \\
\hline
\end{tabular}

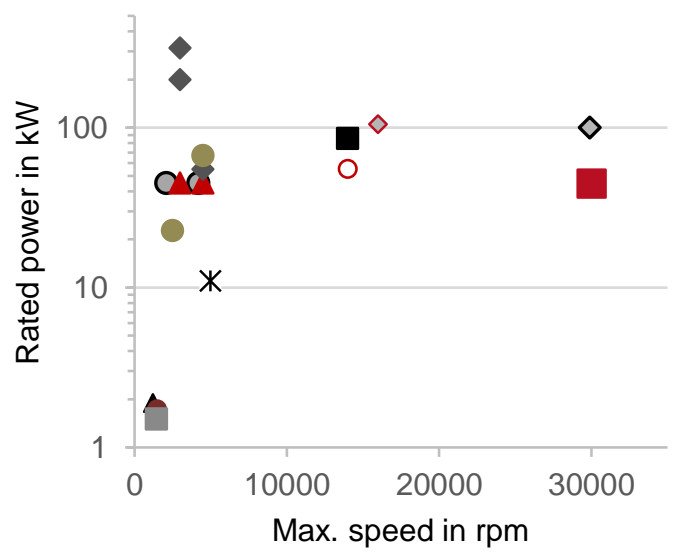

Fig. 1: Synchronous reluctance motors in research and industry based on continuous operation, an overview. 


\section{STATE OF THE ART}

\subsection{High speed SynRM}

The circumferential velocity of high speed electric drives, and not only the rotational speed, is limited according to the rotor topology, geometry, dimensions and to the mechanical material properties of the used electrical steel. The challenge consists in developing a rotor design using strength-enhancing measures. In research and industry applications high speed electric motors are typically asynchronous (ASM) or permanent magnet synchronous motors (PMSM) because of their sturdy design under consideration of the rotor diameter for high circumferential velocity. An energy, resource and cost efficient alternative is a SynRM. Today, also the automotive industry is aware of these benefits including the advantage of low rotor temperature and low mass inertia. Current requirements and trends are high torque, high speeds and low costs for increasing size and mass of cars according to [Hofer 2017]. Here, a frequently used strength-enhancing measure is a bandage made of carbon fibre reinforced plastic (CFRP). In [Hofer 2017] two different SynRM rotor topologies with flux barriers and salient poles for electric traction application are compared regarding high speeds. The flux barrier rotor design is mechanically reinforced with a thin CFRP-sleeve of $2 \mathrm{~mm}$ thickness for a rotor diameter of $160 \mathrm{~mm}$ for rotational speeds up to $16,000 \mathrm{rpm}$. In [Reddy 2015] a flux barrier rotor of a SynRM with a diameter of $200 \mathrm{~mm}$ is presented using a sleeve thickness of $1.0 \mathrm{~mm}$ for a maximum speed of $14,000 \mathrm{rpm}$. For SynRM as motor spindle drives in machine tool application CFRP-bandages are not a suitable solution because of the resulting electromagnetically larger air-gap. Consequently, a higher reactive power is required for magnetic field formation. Further limitations are installation space and no oversizing of the power electronics. In [Sielaff 2017] Sielaff developed a novel SynRM rotor concept that withstands a maximum rotational speed of $16,000 \mathrm{rpm}$ having a rotor outer diameter of $124.2 \mathrm{~mm}$. In addition to the transversally laminated electrical steel packet, thin support sheets having high mechanical material properties are located at equidistant intervals. This results in several packages of electrical sheet metal parts, which are hindered in their radial deformation by the friction contact to the support plates. To avoid radial displacement of the iron segments between the flux barriers, a rigid CFRP rod is inserted into a constructively modified flux barrier (see Fig. 2). The used electrical steel is $\mathrm{NO} 20 \mathrm{HS}$ with a Yield strength of 420 $490 \mathrm{MPa}$.

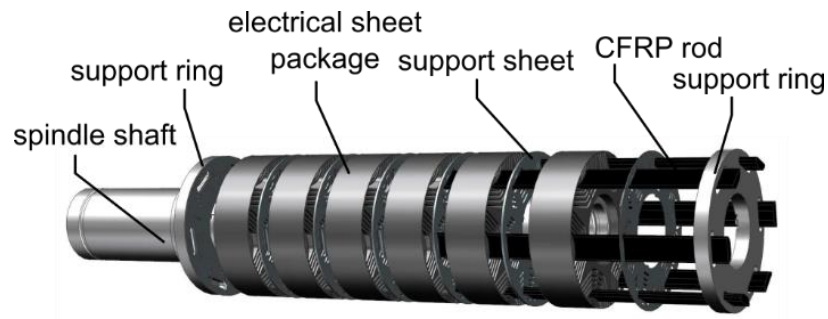

Fig. 2: SynRM motor spindle shaft with novel mechanical support measures [Sielaff 2017].

Winkler and Werner present in [14] two solution approaches for high speed SynRM in motor spindle application. One is a saliency pole rotor topology and the other one is a transversally laminated flux barrier rotor design (see Fig. 3). The used electrical steel is Vacodur 49 with a Yield strength of $390-450 \mathrm{MPa}$. The point of departure for the SynRM development is the comparison with a ASM presenting a rated speed of $29,900 \mathrm{rpm}$ and stator bore diameter of $85 \mathrm{~mm}$. Unfortunately the article of Winkler and Werner does not show any numerical results how the maximum speed can be achieved with the SynRM, especially with the flux barrier variant.
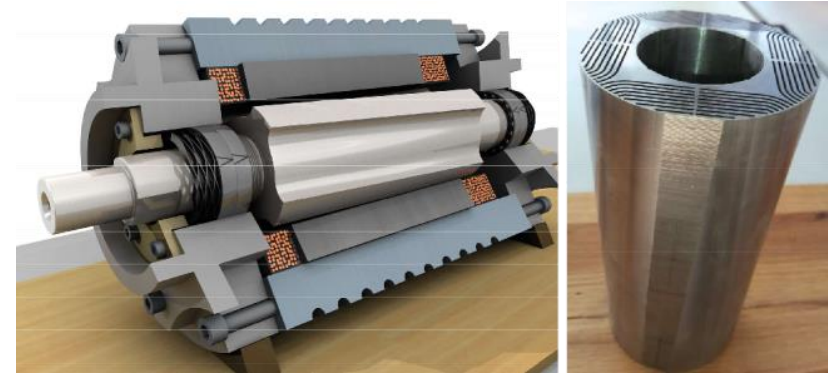

Fig. 3: Saliency pole and flux barrier SynRM as motor spindle drives [Winkler 2018].

\subsection{Testing of high speed drives}

For the practical testing of high speed rotors specific test benches are used. Target parameters of the investigation are maximum rotational speed, radial elastic deformation and rotor concentricity precision. In some cases the material stress is studied. Special measuring equipment and software is required for this purpose as discussed in [Günther 2011]. Commonly used are non-contact measuring principles as capacitive, inductive, eddy current or non-contact optical measuring systems [Günther 2011, Subramani 1997, Schweizer 2009]. The measurement of the radial expansion of electrical steel strip lamination stacks under centrifugal load is challenging. Eddy current and inductive sensors cannot be utilized because of the thin metal sheets and the material properties regarding their high specific electrical resistance and hysteresis losses [Wuppermann 2017]. These sensor types as well as capacitive sensors further depend on the ambient temperature and the dielectric property of the air-gap [Günther 2011]. Optical measurement systems often consist of laser sensors as triangulation sensors, laser Doppler vibrometers or absolute distance or low coherence interferometers [Günther 2011]. Triangulation and low coherence interferometry are not precise enough for measuring fast rotating rotors. Laser Doppler vibrometers are mainly used for vibration measurements [Rothberg 2012]. A common problem that arise with laser sensors measuring fast moving surfaces are its roughness leading to the phenomenon called speckle noise. It occurs when the wavelength of the laser is in the scale of the surface roughness [Günther 2011]. In consequence deformation of smooth ground rotors may be difficult to detect. The choice of sensors for contactless measurement of radial rotor expansion should be based on capacitive sensors or Laser Doppler distance sensors. The latter are used in [Günther 2011].

The centrifugal load test of SynRM flux barrier rotors in this article is carried out on a closed test bench which does not permit any sensor integration. The test bench and measuring environment used is explained in Section 3.

The advantages of synchronous reluctance motors are well known in different industry applications as variable speed drives for pumps and fans, electromobility and motor spindles. The demands on SynRM have been increasing for some years now and show the need for high-speed drives (see Fig 1). According to current research, no SynRM has yet been developed and scientifically tested for an operating speed above $25,000 \mathrm{rpm}$. Within the next 4 sections of this article a novel high speed SynRM for 30,000 rpm is presented. 


\section{SOLUTION APPROACH}

The design of the electro-mechanically optimized SynRM rotor design with flux barriers, radial bridges and roundings is carried out in several iterative steps according to the explanations in [Sielaff 2017]. The main steps are as follows:

- Analytical preliminary design based on the natural course of the magnetic field lines in a full pole rotor by solving the differential equation of the magnetic vector potential, see also [Moghaddam 2011].

- $\quad$ Electrical precision design using ANSYS ${ }^{\circledR}$ Maxwell.

- Mechanical precision design to achieve maximum speeds using ANSYS ${ }^{\circledR}$ Mechanical.

- Parametric multidisciplinary design optimization with optiSlang $^{\circledR}$.

In order to achieve maximum speeds of up to $30,000 \mathrm{rpm}$ with the developed SynRM rotor design, further strengthening measures must be taken into account. Ideally, these should not have any negative effect on the electrical behaviour of the drive. The 3D modelling and its simulation results are validated by centrifugal load tests using SynRM trial rotors which in length are a quarter of the full effective iron length to fit into the test environment. The goal is to compare the rotational speed at which the elastic deformation of the electrical sheets changes into the plastic deformation. Furthermore the results of the practical testing will be used to define a maximum operational speed.

\section{STRUCTURE OF THE SYNRM TRIAL ROTORS}

The machine data of the developed high speed SynRM are listed in the table Tab. 1. The shaft-hub connection is a friction-locked cylindrical interference fit. As shown in Fig 4 the design of the stacked rotor core consists of multiple strength-enhancing measures. Between the sub-packages of slotted electrical sheets there are support plates in full design made of the stainless steel 1.4310 (X10CrNi18-8). These support sheets are used as radial expansion constraint and lateral support with higher oversize than the electrical sheets. The requirements to be met by the support plates are that they should be as narrow as possible for small slumps in air-gap flux density in the longitudinal direction of the rotor [Sielaff 2017]. On the other hand, they must have a certain width in order to develop their supporting effect. Ideal mechanical material properties would be a higher modulus of elasticity and a higher yield strength than the material properties of the electrical sheet. This would result in lower radial elastic deformation and higher load capacity. It is important that the support sheets do not fail before the electrical sheets.

Tab. 1: Machine Data of the six-pole high speed synchronous reluctance motor for motor spindle application.

\begin{tabular}{ll}
\hline Parameter & Value \\
\hline Rated Power & $45 \mathrm{~kW}$ \\
Rated Torque & $19.4 \mathrm{Nm}$ \\
Rated Speed & $22,000 \mathrm{rpm}$ \\
Rated Current & $116 \mathrm{~A}$ (leff Phase) \\
Rated Voltage & $380 \mathrm{~V}$ (Ueff Phase-Phase) \\
Effective iron length & $140 \mathrm{~mm}$ \\
Spindle shaft diameter & $55 \mathrm{~mm}$ \\
Rotor outer diameter & $84.4 \mathrm{~mm}$ \\
\hline
\end{tabular}

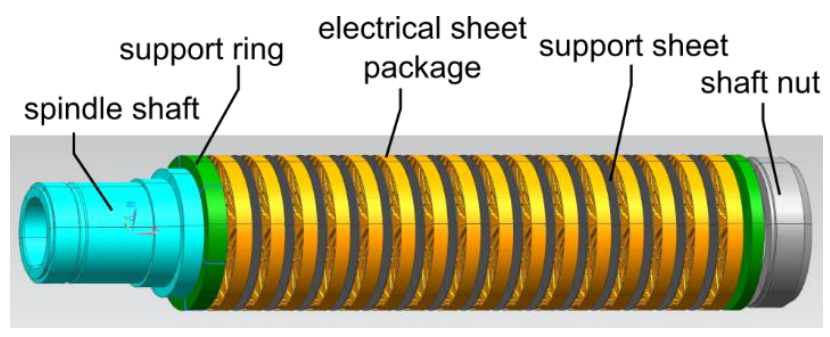

Fig. 4: High speed SynRM motor spindle shaft with novel mechanical support measures including support sheets and a shaft nut.

The NO20HS type electrical sheet used is coated on both sides with bonding varnish called Backlack and is considered high-strength with a guaranteed yield strength of $420 \mathrm{MPa}$. Backlack bonds the lamination stack and leads to a constraint in radial expansion due to the lateral bonding contact of the electrical sheets. The support rings at the beginning and end of the rotor stack serve for the lateral sealing of the flow barriers and the axial force transmission into the electrical sheet packages through the shaft nut by an axial force of $130 \mathrm{kN}$.

For the centrifugal force load tests, four different trial rotor variants were set up and measured before and after mounting the rotor on the probe shaft. They are shown in Fig. 5 and their structure is listed in Tab. 2.

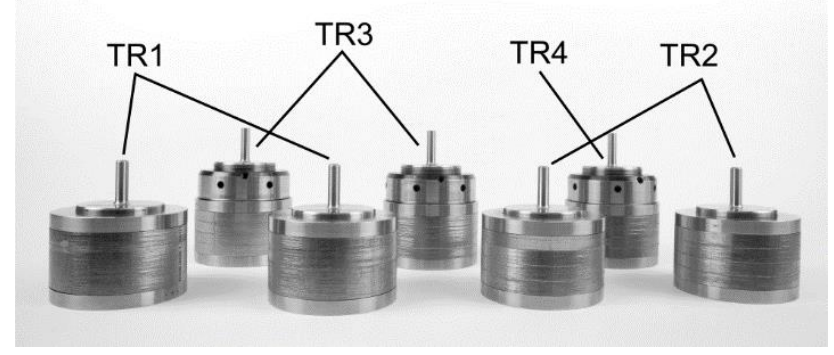

Fig. 5: Four variants of the SynRM trial rotors.

\section{SIMULATION OF THE SYNRM TRIAL ROTORS}

In order to simulate the elastic and initially plastic behaviour as a function of rotational speed, and thus centrifugal force, 3D FEM models of the SynRM trial rotors are built in ANSYS ${ }^{\circledR}$ Mechanical based on CAD data. The mesh setup includes the definition of identical contact cross-links for all component contacts and the specification of an element size of $0.25 \mathrm{~mm}$ in the most critical flux barrier zones at the outer rotor diameter. In total, a mesh with 498,739 nodes and 286,284 elements is created. A bilinear isotropic material behaviour is specified on the basis of the yield strength of $420 \mathrm{MPa}$ and the tangent modulus of $0.902 \mathrm{GPa}$ [Sielaff 2017]. For numerical calculation, a programcontrolled force convergence analysis is performed taking into account large deformations. The ambient temperature is constant at $22^{\circ} \mathrm{C}$.

The meshed 3D FEM model is shown in Fig. 6. As an example, the simulation results of the TR4 trial rotor for radial deformation at the rotor outer diameter and the maximum equivalent stress according to von Mises in the most critical flux barrier zone are shown in Fig 7 and Fig 8. 
Tab. 2: Structure of the SynRM trial rotors.

\begin{tabular}{ccccc}
\hline SynRM trial rotor & shaft material & av. oversize in $\boldsymbol{\mu m}$ & support sheet & shaft nut \\
\hline TR1-1 & $1.3917(\mathrm{Ni42})$ & 43.6 & No & No \\
TR1-2 & $1.3917(\mathrm{Ni42})$ & 39.3 & No & No \\
TR2-1 & $1.3917(\mathrm{Ni42})$ & 44.3 & Yes & No \\
TR2-2 & $1.3917(\mathrm{Ni42})$ & 48.6 & Yes & Yes \\
TR3-1 & $1.3917(\mathrm{Ni42})$ & 45.0 & Yes & Yes \\
TR3-2 & $1.3917(\mathrm{Ni42})$ & 41.3 & Yes & Yes \\
TR4-1 & $1.7131(16 \mathrm{MnCr} 5)$ & 39.3 & & \\
\hline
\end{tabular}

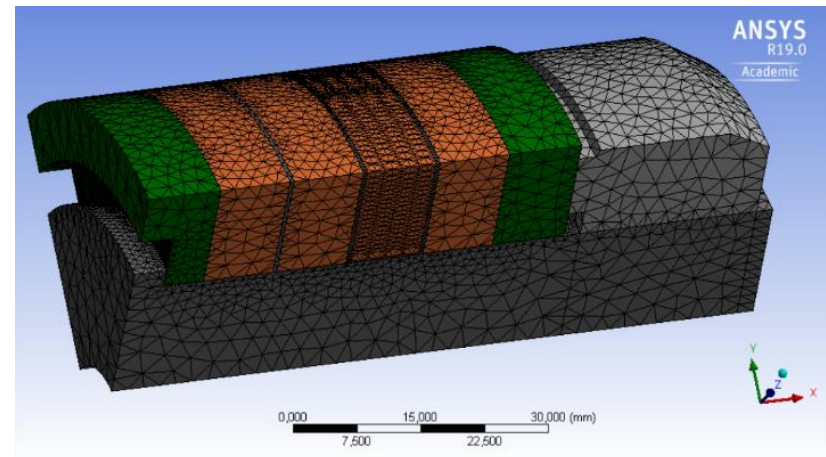

Fig. 6: Meshed 3D-FEM-model of the SynRM trial rotor TR4 with shaft nut and support sheets.

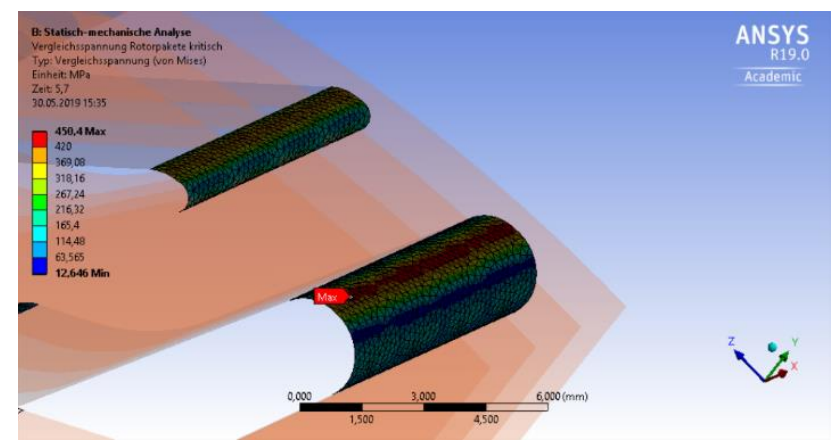

Fig. 7: Most critical flux barrier zone at 30,000 rpm and an equivalent stress von-Mises of $450.4 \mathrm{MPa}$.

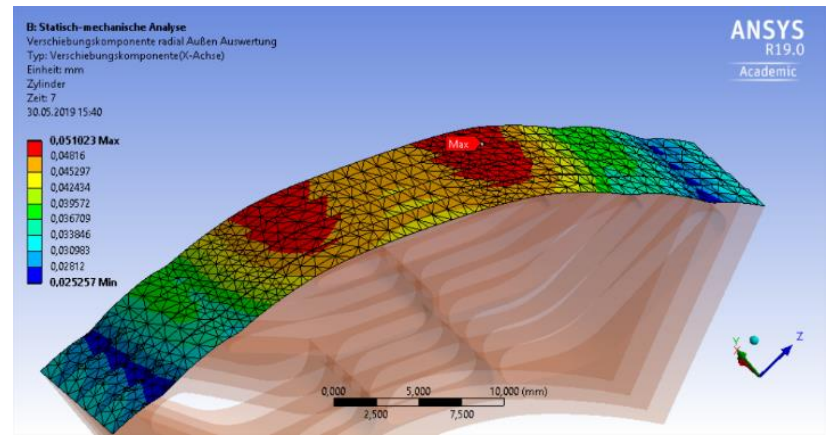

Fig. 8: Maximum radial deformation of $51.0 \mu \mathrm{m}$ of the characteristic wave-shaped contour of the outer rotor diameter.

\section{PRACTICAL CENTRIFUGAL TESTS}

\subsection{Spin and measuring test environment}

The test bench and measurement environment consists of two facilities. After the prober rotors have been dynamically balanced in two planes with a requirement better than G2.5, they are placed in a Schenck EngroTec centrifugal test bench (see Fig 9). The SynRM trial rotors are constantly accelerated at $20 \mathrm{~mm} / \mathrm{s}^{2}$ up to the test speed and turned for $120 \mathrm{~s}$. The rotational speed is increased first in $2,000 \mathrm{rpm}$ steps from the starting speed of $12,000 \mathrm{rpm}$ to $18,000 \mathrm{rpm}$ and afterwards in 1,000 rpm steps. The spinning procedure takes place in a vacuum bunker, so that almost exclusively centrifugal forces act on the rotor with ideal balancing quality.

After each load test at one speed level, the trial rotor is removed from the spin test bench and clamped on a Leitz PMM 864 coordinate measuring machine in a self-centering clamping device (see Fig 9). The contour measurement of the outer radius is carried out in four planes for each electrical steel lamination stack in a circular scan procedure with a scan speed of $2 \mathrm{~mm} / \mathrm{s}$. In the measuring program, the roundness of the SynRM trial rotor is evaluated. The measurement accuracy specified by the manufacturer is $1.20+\mathrm{L} / 300 \mu \mathrm{m}$. The standard measuring deviation of the ruby probe tip with a diameter of $8 \mathrm{~mm}$ calibrated at the beginning of the measurement is $0.7 \mu \mathrm{m}$. Attention was paid to the ambient temperature during the spinning tests, so it was held constant at around $22^{\circ} \mathrm{C}$ depending on the time of day.
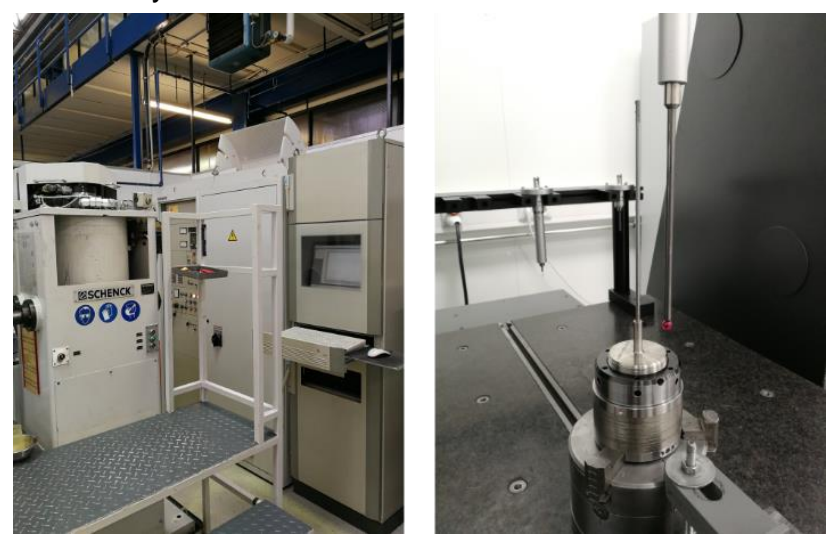

Fig. 9: Test bench for centrifugal load tests (left) and measurement of a trial rotor on the coordinate measuring machine (right).

\subsection{Results}

In this section, the numerical simulation results and the evaluated practical measurements are presented together. This facilitates the comparison between the calculated and the practically determined transition from elastic to plastic deformation as a function of rotational speed.

The results in Fig. 10 illustrate the roundness of the TR4 SynRM trial rotor at the initial stage after mounting and after the spinning test at $32,000 \mathrm{rpm}$. This figure is representative for all other roundness measurements of all SynRM trial rotors. 

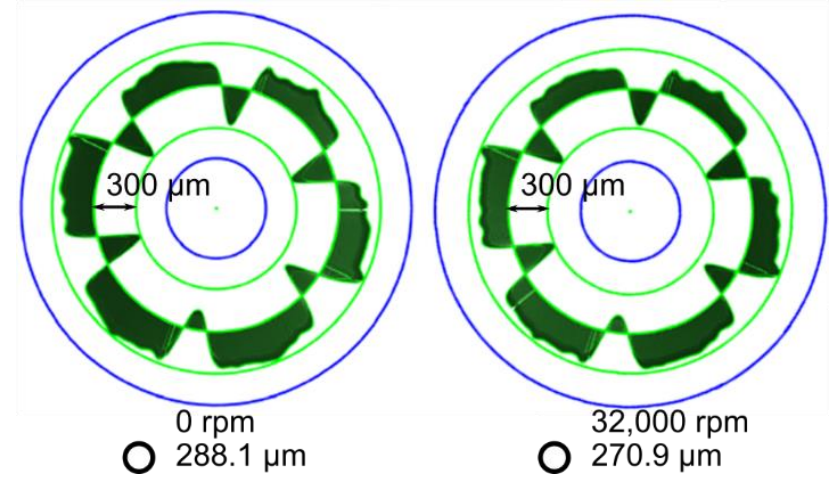

Fig. 10: Roundness of the TR4 SynRM trial rotor as a result of the contour measurement in the first plane near the shaft nut with the Leitz PMM 864 coordinate measuring machine at the initial state and after spinning at $32,000 \mathrm{rpm}$.

The resulting joint pressure in the interference fit after mounting leads to stress on the rotor sheet, which deforms it similarly to under centrifugal load. The numerical calculation results in the most critical flux barrier zone after rotor mounting show a maximum equivalent stress according to von Mises of $330 \mathrm{MPa}$. The stress reserve up to the yield strength is reduced by the friction-locked shafthub connection, and thus the maximum rotational speed of the SynRM. The roundness of the electrical sheet lamination stack decreases from initial state to maximum rotational speed. No plastic deformation can be detected in Fig 10.

In order to evaluate the beginning of the plastic radial deformation, the measurement data of all four circular scans are first averaged for each measuring plane and then the mean values of all planes are averaged again. The result is the graphical curve of the mean radial deformation related to the initial value at $12,000 \mathrm{rpm}$ as shown in Fig. 11.

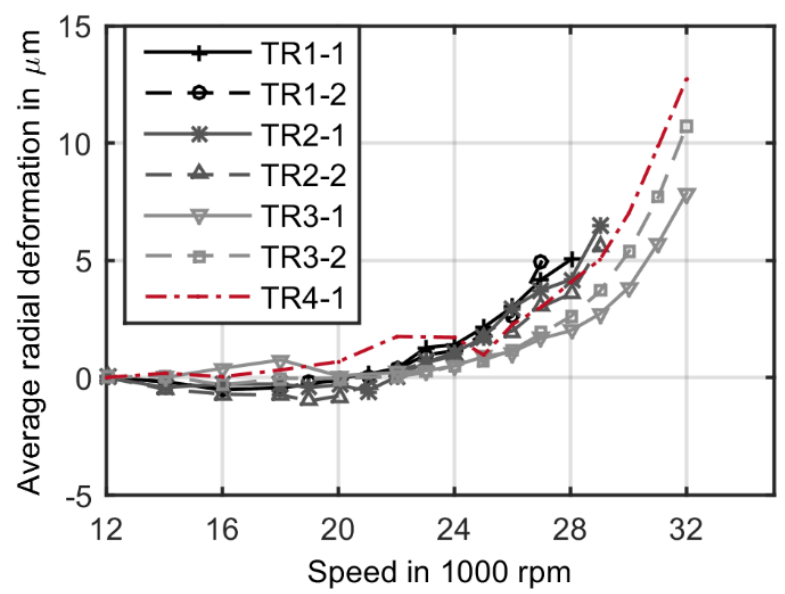

Fig. 11: Average radial deformation of the electrical sheet lamination stack.

First of all, it can be stated that the various strengthenhancing measures have different effects on radial deformation as a function of speed. The TR1 trial rotor variants with only the electrical sheets coated with Backlack show the largest deformations starting at around 23,000 $\mathrm{rpm}$, followed by the TR2 trial rotor variants with additional support sheets. The TR3 and TR4 trial rotor variants with support sheets and shaft nut have the smallest deformations.
Furthermore, it can be concluded how the deformation behaviour responds as a function of the oversize in the interference fit (see Tab 2). For each SynRM trial rotor variant the results are the same. The smaller the interference, the greater the deformations at the outer radius. The initial stress on the electrical sheet is higher with greater interference, whereby the tangential tensile stress in the circumferential tangential bridge is elevated from the outset and thus counteracts radial expansion.

Fig. 12 to 15 show the numerical results of the average radial deformation including elastic and plastic portions and the maximum equivalent stress according to von Mises as a function of rotational speed and in relation to the measured average radial plastic deformation. The numerical calculations were performed by specifying the real average oversize in the 3D FEM model.

The speed with incipient plastic deformation is determined using the trend definition from the quality control chart technique as part of the statistical process control. According to [Dietrich 2014], a trend occurs when seven ascending intervals follow each other. It is then a stability violation which is statistically secured with a residual error probability of less than $0.02 \%$ for a one-sided t-test. The red dotted lines represent the beginning of the plastic deformation in the numerical results of the equivalent stress according to von Mises and in the test results of the permanent radial deformation after spinning.

Only in the case of the TR1-1 trial rotor is the accordance between simulation and experiment data acceptable with a rotational speed difference of $2,000 \mathrm{rpm}$. When comparing the speed limits of the equivalent stresses in Fig 13 and Fig. 14, it is noticeable that the simulation of the actually improved trial rotor variant TR3-1 with shaft nut has a lower limit at 15,000 rpm compared to TR2-1 at 16,000 rpm. This does not correspond to the expectation and the experimental measurement results. The error lies in the modelling of the axial surface contacts between the electrical and the support sheets. Since the calculation of adhesive contacts by delamination in ANSYS ${ }^{\circledR}$ Mechanical is problematic due to unknown material properties and timeconsuming, the connections for the trial rotor variants TR1 and TR2 were modelled as a bonded contact. For the trial rotor variants TR3 and TR4, a frictional contact with a coefficient of friction of 0.2 for steel was generated instead. The axial force applied by the shaft nut causes frictional forces between the sheets which are opposite in direction to the radial centrifugal force.

The influence of the shaft material on the speed representing the beginning of plastic deformation can be taken into account when designing the interference fit and defining the tolerance field. In this way a systematic deviation can be excluded, whereby essentially the random variance of the value of the oversize in the tolerance field from production remains. TR3-1 and TR4-1 have the same rotor structure except for the shaft material and thus the necessary difference in the tolerance field for nearly the same maximum speed. Due to the smaller oversize of TR41 , the deformation remains elastic up to a speed of 25,000 rpm in Fig. 15, whereas with TR3-1 it only remains elastic up to 23,000 rpm in Fig. 14. 


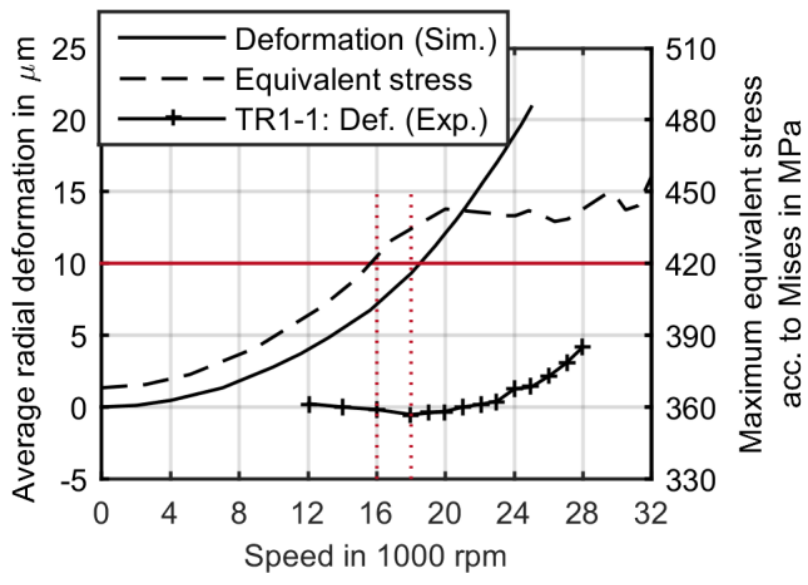

Fig. 12: Definition of the beginning of the plastic deformation for SynRM trial rotor TR1-1 with an average oversize of $43.6 \mu \mathrm{m}$.

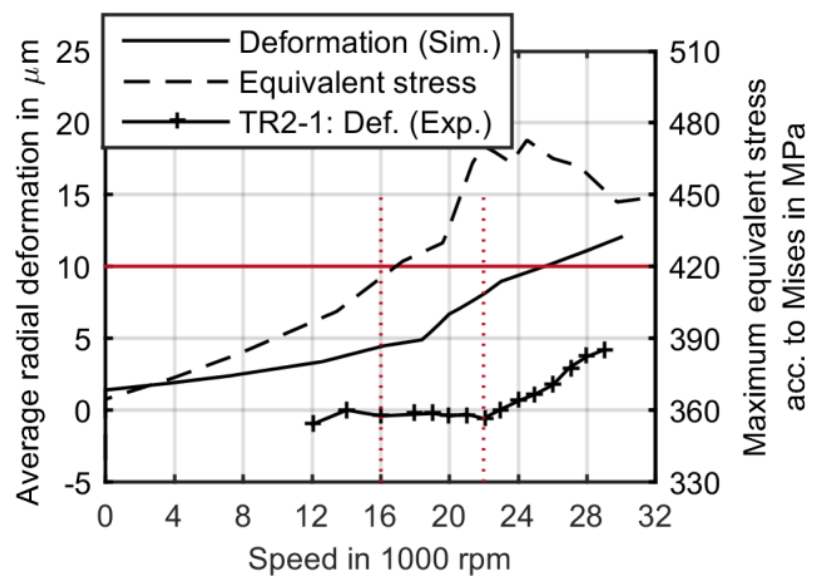

Fig. 13: Definition of the beginning of the plastic deformation for SynRM trial rotor TR2-1 with an average oversize of $44.3 \mu \mathrm{m}$.

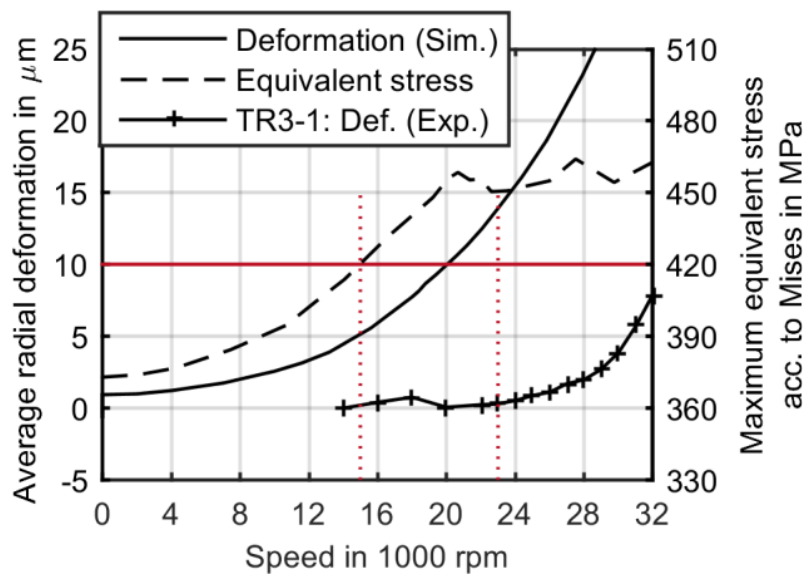

Fig. 14: Definition of the beginning of the plastic deformation for SynRM trial rotor TR3-1 with an average oversize of $45.0 \mu \mathrm{m}$.

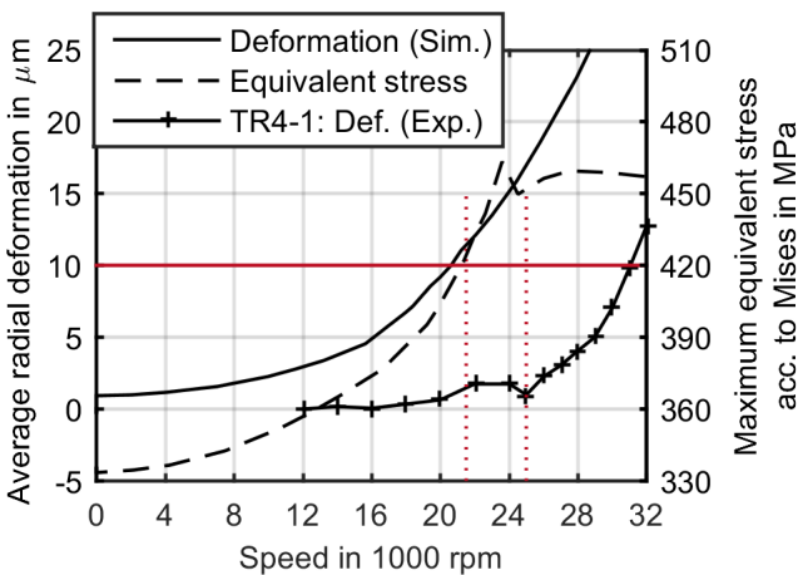

Fig. 15: Definition of the beginning of the plastic deformation for SynRM trial rotor TR4-1 with an average oversize of $39.3 \mu \mathrm{m}$.

\section{CONCLUSION}

This article gives an insight into the elastic and plastic deformation behaviour of electrical steel strip lamination stacks with Backlack. Numerical and experimental investigations have been carried out. The interpretation of the test results allow an estimation of the effect of strengthenhancing measures on the maximum operating speed until plastic deformation starts. For trial rotor variants with support sheets and shaft nut maximum operating speeds of up to $25,000 \mathrm{rpm}$ can be achieved.

New SynRM rotor flux barrier designs could be developed in the future that take into account the initial rotor sheet stress by the resulting joint pressure.

The adaptation of simulation results to test results through improved modelling of the flat electrical sheet contacts is the subject of current research activities.

\section{ACKNOWLEDGEMENT}

The authors would like to thank the AiFForschungsvereinigung for managing the cooperative project within ZIM, the Central Innovation Programme for SMEs. This work is supported by the Federal Ministry of Economics and Energy by resolution of the German Bundestag.

\section{REFERENCES}

[ABB 2019] ABB. IE4 - Antriebspaket mit Synchronreluktanzmotor und Frequenzumrichter, [online] https://new.abb.com/docs/default-source/automationpower-world-switzerland-docs/antriebspaket-mitsynchronreluktanzmotor-und-

frequenzumrichter.pdf?sfvrsn=2 [31/05/2019]

[Abele 2018] Abele, E., Baier C. Zerspanung mit Industrierobotern. Werkstattstechnik online: wt, 2018, Vol.108, No.6, pp 429-435, ISSN 1436-4980

[Boglietti 2005] Boglietti, A., Cavagnino, A., Pastorelli, M., Vagati, A. Experimental comparison of induction and synchronous reluctance motors performance, Fourtieth IAS Annual Meeting. Conference Record of the 2005 Industry Applications Conference, Oct 2005, Vol.1, pp 474-479, ISSN 0197-2618

[Boldea 1991] Boldea, I., Nasar S. A. Emerging Electric Machines with Axially Laminated Anisotropic Rotors: A 
Review, In: Electric Machines and Power Systems, 1991, Vol.19, No.6, pp 673-703

[Dietrich 2014] Dietrich, E., Schulze, A. Statistische Verfahren zur Maschinen- und Prozessqualifikation, aktualisierte 7. Auflage. München: Hanser, 2014, ISBN-10: 9783446440555

[Günther 2011] Günther, P., Dreier, F., Pfister, T., et al. Measurement of radial expansion and tumbling motion of a high-speed rotor using an optical sensor system, Mechanical Systems and Signal Processing, Jan 2011, Vol.25, No.1, pp 319-330, ISSN 0888-3270

[Hofer 2017] Hofer, M., Schroedl, M. Comparison of a flux barrier and a salient pole synchronous reluctance machine for high rotational speeds in electric traction applications. In: 2017 20th International Conference on Electrical Machines and Systems (ICEMS), Aug 2017

[IEC 61800-9-1 2017] IEC 61800-9-1:2017. Adjustable speed electrical power drive systems - Part 9-1: Ecodesign for power drive systems, motor starters, power electronics and their driven applications - General requirements for setting energy efficiency standards for power driven equipment using the extended product approach (EPA) and semi analytic model (SAM), Mar 2017

[IEC TS 60034-30-2 2016] IEC TS 60034-30-2:2016. Rotating electrical machines - Part 30-2: Efficiency classes of variable speed AC motors (IE-code), Dec 2016

[KSB 2019] KSB. KSB SuPremE, [online] https://products.ksb.com/de-de/produkte/pumpen-und-

pumpensysteme/steuer-regel-und-

diagnosesysteme/pumpenregelung/laufwerkemotoren/ksb-supreme-3456 [31/05/2019]

[Matsuo 1993] Matsuo, T., Lipo, T. A. Field oriented control of synchronous reluctance machine. In: Power Electronics Specialists Conference, Jun 1993, PESC '93 Record, 24th Annual IEEE, pp 425-431

[Moghaddam 2011] Moghaddam, R. R. Synchronous Reluctance Machine (SynRM) in Variable Speed Drives (VSD) Applications, KTH Royal Institute of Technology, 2011

[Neusüs 2018] Neusüs, S., Binder, A. Design of a synchronous reluctance rotor for the stator of an $11 \mathrm{~kW}$ induction machine, e \& i Elektrotechnik und Informationstechnik, Apr 2018, Vol.135, No.2, pp 177-186, ISSN 1613-7620

[Reddy 2015] Reddy, P. B., Grace, K., Refaie, A. E. Conceptual Design of Sleeve rotor Synchronous Reluctance Motor for Traction Applications. In: 2015 IEEE International Electric Machines \& Drives Conference (IEMDC), May 2015, pp 195-201

[Rothberg 2012] Rothberg, S. J., Halkon, B. J., Tirabassi, M., Pusey, C. Radial vibration measurements directly from rotors using laser vibrometry: The effects of surface roughness, instrument misalignments and pseudovibration, Mechanical Systems and Signal Processing, 2012, Vol.33, pp 109-131, ISSN 0888-3270

[Schweizer 2009] Schweizer, B., Sievert M. Nonlinear oscillations of automotive turbocharger turbines, Journal of Sound and Vibration, 2009, Vol.321, No.3, pp 955-975, ISSN 0022-460X

[Sebest 2016] Sebest, M., Hrabovcova, V., Makys, P. Optimization of the reluctance synchronous motor with barriers rotor, 2016 ELEKTRO, May 2016, pp 374-378, ISBN 978-1-4673-8698-2

[Sielaff 2017] Sielaff, T. Zum Einsatz von Synchronreluktanzmotoren in Motorspindeln für UniversalBearbeitungszentren, Technische Universität Darmstadt, 2017, ISBN 3844053433

[Siemens 2019] Siemens. Das innovative Synchronreluktanz-Antriebssystem mit SIMOTICS Motoren und SINAMICS Umrichtern, [online] https://w3app.siemens.com/mcms/infocenter/content/de/S eiten/order_form.aspx?nodeKey=key_516797\&infotype=br ochures\&linkit=97149243-7eab-47b5-b849-4291e85316ae [31/05/2019]

[Subramami 1997] Subramani, D. A., Ramamurti, V., Sridhara, K. Numerical analysis and experimental verification of the radial growth of a turbocharger centrifugal compressor impeller, The Journal of Strain Analysis for Engineering Design, 1997, Vol.32, No.2, pp 119-128

[Winkler 2018] Winkler, S., Werner, R. Hochtourige Reluktanzmotoren für den Einsatz als Spindelantriebe, Antriebstechnik, Oct 2018, Vol.10, pp 90-95

[Wuppermann 2017] Wuppermann, C.-D.; Schoppa, A., Wirtschaftsvereinigung Stahl (Hrsg.): Elektroband und Blech, Merkblatt 401, 2017, ISSN 0175-2006 